\title{
A Fuzzy Multi-Criteria SWOT Analysis: An Application to Nuclear Power Plant Site Selection
}

\author{
Mehmet Ekmekçioğlü \\ Department of Production Planning, FORD OTOSAN \\ Golcuk, Izmit, 41650, Turkey \\ Ahmet Can Kutlu \\ Department of Industrial Engineering, Istanbul Technical University \\ Macka, Istanbul, 34367, Turkey \\ Cengiz Kahraman \\ Department of Industrial Engineering, Istanbul Technical University \\ Macka, Istanbul, 34367, Turkey \\ Received 11 March 2011 \\ Accepted 19 June 2011
}

\begin{abstract}
SWOT (Strengths, Weaknesses, Opportunities and Threats) analysis is a commonly used and an important technique for analyzing internal and external environments in order to provide a systematic approach and support for a decision making. SWOT is criticized mostly for considering only qualitative examination of environmental factors, no priority for various factors and strategies, and no vagueness of the factors under fuzziness. In this paper, fuzzy TOPSIS (Technique for Order Preference by Similarity to Ideal Solution) integrated with fuzzy AHP (Analytical Hierarchy Process) is used to develop fuzzy multi-criteria SWOT analysis in order to overcome these shortcomings. Nuclear power plant site selection, which is a strategic and important issue for Turkey's energy policy making, is considered as an application case study that demonstrated the applicability of the developed fuzzy SWOT model.
\end{abstract}

Keywords: Fuzzy SWOT, Fuzzy AHP, Fuzzy TOPSIS, Nuclear Power Plant, Site Selection.

*Corresponding author. Tel.: +90 5067622584 E-mail: meceng3584@yahoo.com, ekmekciogl@itu.edu.tr 


\section{Introduction}

SWOT analysis is a commonly used and important technique for analyzing internal and external environments in order to provide a systematic approach and support for a decision making. ${ }^{1,2,3,4,5}$ This approach involves systematic thinking and comprehensive diagnosis of factors related to a new product, technology, management, or planning. ${ }^{6}$ SWOT, commonly known in strategic management area, analyzes the opportunities and threats identified by an internal environment appraisal as well as the strengths and weaknesses by an external environment appraisal. ${ }^{7,8}$ The external and internal environments include variables which are outside and inside the organization, respectively. The top management of the organization cannot affect either type of the variable for a shortterm. ${ }^{9}$

SWOT, an early stage of the strategic planning process, has the goal of developing and adopting a strategy resulting in a good fit between internal and external factors. ${ }^{4}$ SWOT maximizes strengths and opportunities, and minimizes threats and weaknesses. In other words, it transforms weaknesses into strengths, and threats into opportunities. ${ }^{10-11}$ SWOT can also be used when strategy alternative suddenly arises and the decision context relevant to it has to be analyzed. ${ }^{11}$

In a conventional SWOT analysis, the magnitude of the factors is not quantified to determine the effect of each factor on the proposed plan or strategy. ${ }^{12}$ In other words, SWOT analysis does not provide an analytical means to determine the relative importance of the factors, or the ability to assess the appropriateness of decision alternatives based on these factors. ${ }^{13}$ Kurtila et al. $(2000)^{4}$ presented a new hybrid method that eliminates the weaknesses in the measurement and evaluation steps of the SWOT analysis and this technique involves the utilization of the analytic hierarchy process (AHP) in the SWOT analysis and has been referred to as A'WOT in subsequent studies. ${ }^{13,14}$ Chang and Huang (2006) ${ }^{15}$ used the quantified SWOT analytical method adapted to the Multi-Attribute Decision Making concept. AHP and a multi-layer scheme for the simplification of the complex problems are utilized. ${ }^{7}$ Furthermore analytical network process (ANP) in a SWOT analysis was suggested by Yüksel and Dağdeviren (2007). ${ }^{16}$
While the proper use of SWOT is a good basis for strategy formulation, ${ }^{13}$ it still has certain structural problems. The majority of papers assume that the demand is deterministic, but in reality this assumption is not true. ${ }^{17}$ An important problem is the lack of considering uncertain and two sided factors and there is a lack of prioritization of the factors and strategies and there are too many extractable strategies. ${ }^{1}$ Despite its wide applications, Hill and Westbrook $(1997)^{18}$ mention seven problems of the SWOT method and most important ones are as follows:

(i) Usually only qualitative examination of environmental factors is considered; ${ }^{19}$

(ii) It considers no priority for various factors and strategies;

(iii) It does not consider the vagueness of the factors.

In this paper, a model is proposed for quantified SWOT under fuzziness. After internal and external criteria are determined, Buckley's fuzzy $\mathrm{AHP}^{20}$ is utilized to determine the weight vector of each type of criteria. Later, by using the linguistic scores of each strategic alternative for both internal and external criteria, and the weight vector of each type of criteria, Chen's fuzzy TOPSIS $^{21}$ is utilized. According to the ranking results the degree of internal dimension scores from weakness to strength and the degree of external dimension scores from threats to opportunities are obtained. At last, the strategic alternative is selected with the largest strength and opportunity scores.

The rest of the paper is organized as follows. In Section 2, Literature Reviews of Fuzzy SWOT, Fuzzy AHP and Fuzzy TOPSIS are expressed. In Section 3, the fuzzy multi-criteria SWOT analysis is modeled by explaining fuzzy AHP, fuzzy TOPSIS and the proposed methodology. In Section 4, nuclear power plant site selection, which is a strategic and important issue for Turkey's energy policy making, is considered as an application case of our proposed methodology. Finally, conclusions are given.

\section{Literature Review}

\subsection{Fuzzy SWOT}

In SWOT analysis some uncertainties can be encountered in the evaluation of an organization's internal and external environment. It can be stated that it is impossible for the opportunities and threats arising 
from the external environment of the firm to be always definite in any condition. Consequently, it is also impossible to measure the numerical values precisely. Similarly, it is not always possible to measure or evaluate the strengths and weaknesses which are the consequences of the assets and abilities of the firm exactly. ${ }^{1}$ Besides, in SWOT analysis, it is difficult to evaluate the factors in any case and at anytime in a binary based Aristotle logic. For instance, it may not be realistic to represent the image about the goods and services produced by a firm in two points as sufficient (1) or insufficient (0). In real life, there may be different evaluations between these two. Therefore, it will not be possible to understand the actual situation with an evaluation which does not assume fuzziness. ${ }^{1}$

Ghazinoory et al. (2007) $)^{1}$ emphasized that in most cases the internal and external factors cannot be fully recognized as positive or negative, as their impact on the organization could be observed within a wide spread which may include both positive and negative effects and they presented a fuzzy SWOT algorithm considering uncertain and two-sided factors, and prioritization of that factors and strategies. Strategies to reduce the dangers of transporting hazardous material in Iran are made by Kheirkhah et al. (2009) ${ }^{22}$ by using the method of fuzzy SWOT analysis. A fuzzy quantified SWOT analytical procedure that integrates the MCDM concept and fuzzy method to help decision makers assess the competitive position and degree of locations developing internal distribution centers (IDC) is proposed by Kuo-liang and Shu-chen (2008). ${ }^{23}$ By using this method the environmental position of locations developing IDCs can be judged according to their environmental position and competitive degree in four quadrants, and competitive strategies further developed to strengthen competitive advantage in accordance with the grand strategy matrix (GSM) model. A new fuzzy quantified SWOT procedure that integrates the fuzzy ANP method to help decision makers assess the competitive position and degree of each transportation industry developing in Taiwan's transportation market is presented by Kuo et al. (2009). ${ }^{24}$ The proposed model can handle the criteria characteristics, which may be independent, dependent and interdependent. A two phased decision model for supplier selection is proposed by Amin et al. (2011). ${ }^{7}$ In first phase, fuzzy quantified SWOT analysis is applied for evaluating suppliers. The output of this stage is the weight of each supplier. In second phase a fuzzy linear programming model is applied to determine the order quantity.

\subsection{Fuzzy AHP}

AHP is one of the well-known multi-criteria decision making techniques that was first proposed by Saaty $(1980)^{25}$. The classical AHP takes into consideration the definite judgments of decision makers. ${ }^{26}$ Although the classical AHP includes the opinions of experts and makes a multiple criteria evaluation; it is not capable of reflecting human's vague thoughts. ${ }^{27}$

As the uncertainty of information and the vagueness of human feeling and recognition, it is difficult to provide exact numerical values for the criteria and to make evaluations which exactly convey the feeling and recognition of objects for decision makers. Therefore, most of the selection parameters cannot be given precisely. Thus experts may prefer intermediate judgments rather than certain judgments. So the fuzzy set theory makes the comparison process more flexible and capable to explain experts' preferences. ${ }^{28}$

Different methods for the fuzzification of AHP have been proposed in the literature. AHP is firstly fuzzified by Laarhoven and Pedrycz $(1983)^{29}$ and in this study, fuzzy ratios which were defined by triangular membership functions were compared. This method was subjected Buckley $(1985)^{20}$ stating that the linear equations of obtained equations do not always unique solution and their insistence on triangular fuzzy numbers. Buckley $(1985)^{20}$ uses the comparison ratios based on trapezoidal membership functions. A new approach was introduced by Chang $(1996)^{30}$ for handling fuzzy AHP, with the use of triangular fuzzy numbers for pair-wise comparison scale of fuzzy AHP, and the use of the extent analysis method for the synthetic extent values of the pair-wise comparisons. A fuzzy objective and subjective method based on fuzzy AHP was proposed by Kahraman et al. $(1998)^{31}$ A selection among the transportation companies is analyzed in the study of Kulak and Kahraman (2005) by using fuzzy axiomatic design and fuzzy AHP. They developed a fuzzy multi-attribute axiomatic design approach and compared it with fuzzy AHP.

\subsection{Fuzzy TOPSIS}

TOPSIS, one of the classical Multi-criteria decision making methods, was developed by Hwang and Yong (1981). ${ }^{33}$ It is based on the concept that the chosen 
alternative should have the shortest distance from the positive ideal solution (PIS) and the farthest from the negative ideal solution (NIS). TOPSIS also provides an easily understandable and programmable calculation procedure. It has the ability of taking various criteria with different units into account simultaneously. ${ }^{34}$

A number of fuzzy TOPSIS methods have been developed in recent years. Fuzzy numbers to establish fuzzy TOPSIS was first applied in Chen and Hwang (1992). ${ }^{35}$ A fuzzy TOPSIS method developed by Triantaphyllou and Lin $(1996)^{36}$ where relative closeness for each alternative is evaluated based on fuzzy arithmetic operations. Chen (2000) $)^{21}$ extends the TOPSIS method to fuzzy group decision making situations by considering triangular fuzzy numbers and defining crisp Euclidean distance between two fuzzy numbers. The methodology proposed by Chen $(2000)^{21}$ is further improved in some studies. ${ }^{37-38}$ In addition the fuzzy TOPSIS method is extended based on alpha level sets with interval arithmetic. ${ }^{39-40}$

Fuzzy TOPSIS has been introduced for various multi-attribute decision-making problems. Fuzzy TOPSIS is used for plant location selection ${ }^{41}$ and for supplier selection. ${ }^{42}$ Fuzzy TOPSIS also is utilized for industrial robotic system selection. ${ }^{43}$ Moreover Kaya $(2010)^{44}$ uses a multi-attribute e-business website quality evaluation methodology based on a modified fuzzy TOPSIS approach. Perçin and Kahraman (2010) ${ }^{45}$ propose fuzzy TOPSIS for six sigma projects selection. Ekmekçioğlu et al. $(2010)^{34}$ use a modified fuzzy TOPSIS to select municipal solid waste disposal method and site. Furthermore fuzzy TOPSIS integrated with fuzzy AHP is used to propose a new FMEA (failure modes and effects analysis) which overcomes the shortcomings of traditional FMEA. ${ }^{46}$ Another modified fuzzy TOPSIS for selection of the best energy technology alternative is proposed by Kaya and Kahraman (2011). ${ }^{47}$ Fuzzy TOPSIS is used for modeling consumer's product adoption process. ${ }^{48}$

\section{Fuzzy Multi-criteria Analysis}

To overcome the shortcomings of SWOT analysis, a fuzzy multi-criteria SWOT approach is proposed in this paper. Firstly, internal and external criteria are determined as it was in traditional SWOT analysis. Then, after appropriate linguistic scores of each criterion are determined, Buckley's fuzzy $\mathrm{AHP}^{20}$ is utilized to determine the weight vector of each type of criteria. Later, by using the linguistic scores of each strategic alternative for both internal and external criteria, and the weight vector of each type of criteria, Chen's fuzzy TOPSIS ${ }^{21}$ is utilized. According to the ranking results the degree of internal dimension scores from weakness to strength and the degree of external dimension scores from threats to opportunities are obtained. At last, the strategic alternative is selected with the largest strength and opportunity scores.

\subsection{Fuzzy AHP}

Buckley $(1985)^{20}$ uses the geometric mean method to derive fuzzy weights and performance scores. This method is selected due to its easy use to extend to the fuzzy case and guarantee a unique solution to the reciprocal comparison matrix. The weight assessing method by geometric mean is chosen for its simplicity and ease in its application to the fuzzy case. The positive reciprocal comparison matrix of criteria weights is given as:

$$
C=\left[\begin{array}{cccc}
C_{11} & C_{12} & \cdots & C_{1 n} \\
C_{21} & C_{22} & \cdots & C_{2 n} \\
\vdots & & & \vdots \\
C_{n 1} & C_{n 2} & \cdots & C_{n n}
\end{array}\right]
$$

The geometric mean of each row is calculated as:

$$
z_{j}=\left[\prod_{k=1}^{n} C_{j k}\right]^{1 / n} \text { for } j, k=1,2, \ldots, n
$$

The weight $\mathrm{w}_{\mathrm{j}}$ is calculated as:

$$
w_{j}=\frac{z_{j}}{z_{1}+z_{2}+\ldots+z_{n}}, \quad \forall j .
$$

To facilitate the calculation of fuzzy weights, the following arithmetic operations of trapezoidal fuzzy numbers are presented. A trapezoidal fuzzy number ( $\operatorname{TrFN})$ can be defined as $\tilde{m}=(a, b, c, d)$ where $0 \leq a \leq b \leq c \leq d$

In the following, Buckley's (1985) method ${ }^{20}$ is explained in the following steps:

Step 1: Evaluate the relative importance of the criteria using pair-wise comparisons. The experts are required to provide their judgments on the basis of their knowledge and expertise. The experts' linguistic preferences are converted into trapezoidal fuzzy numbers using Table 1. 
Table 1. Fuzzy evaluation scores for the weight vector.

\begin{tabular}{lc}
\hline Linguistic terms & Fuzzy score \\
\hline Absolutely Strong (AS) & $(2,2,25,2,75,3)$ \\
Very Strong (VS) & $(1,5,1,75,2,25,2,5)$ \\
Fairly Strong (FS) & $(1,1,25,1,75,2)$ \\
Slightly Strong (SS) & $(1,1,25,1,25,1,5)$ \\
Equal (E) & $(1,1,1,1)$ \\
Slightly Weak (SW) & $(2 / 3,1,1,1)$ \\
Fairly Weak (FW) & $(1 / 2,2 / 3,0,85,1)$ \\
Very Weak (VW) & $(2 / 5,1 / 2,3 / 5,2 / 3)$ \\
Absolutely Weak (AW) & $(1 / 3,2 / 5,0,45,0,5)$ \\
\hline
\end{tabular}

Step 2: Aggregate experts' individual preferences into group preference by applying the fuzzy trapezoidal averaging operator, which is defined by

$$
\widetilde{C}_{j k}=\frac{1}{K}\left[\widetilde{C}_{j k}^{1}(+) \widetilde{C}_{j k}^{2}(+) \ldots(+) \widetilde{C}_{j k}^{K}\right]
$$

where $K$ is the number of experts and $\widetilde{C}_{j}^{K}$ is the evaluation of the $K^{\text {th }}$ decision maker on the pairwise importance comparison of $j^{\text {th }}$ and $k^{\text {th }}$ criteria.

Step 3. Obtain the fuzzy weights $\widetilde{w}_{j}$. The derivation of $\widetilde{z}_{j}$ values (Eq. 2) and fuzzy weights $\widetilde{w}_{j}$ (Eq. 3) can be detailed as follows. Let,

$$
a_{j}=\left[\prod_{j=1}^{n} \tilde{a}_{j k}\right]^{1 / n}
$$

and

$$
a=\sum_{j=1}^{n} a_{j} .
$$

Similarly, $b_{\mathrm{j}}$ and $b, c_{\mathrm{j}}$ and $c, d_{\mathrm{j}}$ and $d$ can be defined. The fuzzy weight $w_{\mathrm{j}}$ is determined as

$$
w_{j}=\left(\frac{d_{j}}{d}, \frac{c_{j}}{c}, \frac{b_{j}}{b}, \frac{a_{j}}{a}\right), \text { each } \mathrm{j}
$$

Step 4. Defuzzify and normalize the trapezoidal fuzzy weights. To defuzzify the TrFN in Eq. (7), Eq. (8) is used:

$$
w_{j}^{\prime}=\frac{\frac{a_{j}}{d}+2\left(\frac{b_{j}}{c}+\frac{c_{j}}{b}\right)+\frac{d_{j}}{a}}{6}
$$

Now, to normalize the crisp weights Eq. (9) is used:

$$
w_{j}=\frac{w_{j}^{\prime}}{\sum_{j=1}^{n} w_{j}^{\prime}}, \quad j=1,2, \ldots, n
$$

After the deffuzzification of each value in the matrix, CR of the matrix can easily be calculated and checked whether CR is smaller than .10 or not.

\subsection{Fuzzy TOPSIS}

In the following, Chen's fuzzy TOPSIS method ${ }^{21}$ is explained:

Chen $(2000)^{21}$ extends the TOPSIS method to fuzzy group decision making situations by considering triangular fuzzy numbers and defining crisp Euclidean distance between two fuzzy numbers. In Chen's fuzzy TOPSIS $^{21}$, linguistic preferences can easily be converted to fuzzy numbers which are allowed to be used in calculations. $^{36-46-48}$

It is suggested that the decision makers use linguistic variables to evaluate the ratings of alternatives with respect to criteria. Table 2 gives the linguistic scale for evaluation of the alternatives. Assuming that a decision group has $\mathrm{K}$ people, the ratings of alternatives with respect to each criterion can be calculated as;

$$
\tilde{x}_{i j}=\frac{1}{K}\left[\tilde{x}_{i j}^{1}(+) \tilde{x}_{i j}^{2}(+) \ldots(+) \tilde{x}_{i j}^{K}\right]
$$

where $\tilde{x}_{i j}^{K}$ is the rating of the $K^{\text {th }}$ decision maker for $i^{\text {th }}$ alternative with respect to $j^{\text {th }}$ criterion. ${ }^{21}$

Table 2. Fuzzy evaluation scores for the alternatives.

\begin{tabular}{lc}
\hline Linguistic terms & Fuzzy score \\
\hline Very Poor (VP) & $(0,0,1)$ \\
Poor (P) & $(0,1,3)$ \\
Medium Poor (MP) & $(1,3,5)$ \\
Fair (F) & $(3,5,7)$ \\
Medium Good (MG) & $(5,7,9)$ \\
Good (G) & $(7,9,10)$ \\
Very Good (VG) & $(9,10,10)$ \\
\hline
\end{tabular}

Obtaining weights of the criteria and fuzzy ratings of alternatives with respect to each criterion, the fuzzy multi-criteria decision-making problem can be expressed in matrix format as,

$$
D=\left[\begin{array}{cccc}
\tilde{x}_{11} & \tilde{x}_{12} & \cdots & \tilde{x}_{1 n} \\
\vdots & \vdots & \cdots & \vdots \\
\tilde{x}_{m 1} & \tilde{x}_{m 2} & \cdots & \tilde{x}_{m n}
\end{array}\right],
$$

$$
W=\left[w_{1}, w_{2}, \ldots, w_{n}\right], \quad j=1,2, \ldots, n,
$$

where $\tilde{x}_{i j}$ is the rating of the alternative $A_{i}$ with respect to criterion $j$ (i.e. $C_{j}$ ) and $w_{j}$ denotes the importance weight of $C_{j}$. These linguistic variables can be described by triangular fuzzy numbers: $\tilde{x}_{i j}=$ $\left(a_{i j}, b_{i j}, c_{i j}\right)$. To avoid the complicated normalization formula used in classical TOPSIS, the linear scale transformation is used here to transform the various criteria scales into a comparable scale. Therefore, we 
can obtain the normalized fuzzy decision matrix denoted by $\tilde{R}$.

$$
\tilde{R}=\left[\tilde{r}_{i j}\right]_{m x n},
$$

where $B$ and $C$ are the set of benefit criteria and cost criteria, respectively, and

$$
\begin{aligned}
& \tilde{r}=\left(\frac{\tilde{a}_{i j}}{c_{j}^{*}}, \frac{\tilde{b}_{i j}}{c_{j}^{*}}, \frac{\tilde{c}_{i j}}{c_{j}^{*}}\right), \quad j \epsilon B ; \\
& \tilde{r}=\left(\frac{a_{j}^{-}}{c_{i j}}, \frac{a_{j}^{-}}{b_{i j}}, \frac{a_{j}^{-}}{a_{i j}}\right), \quad j \epsilon C ; \\
& c_{j}^{*}=\max _{i} c_{i j} \quad \text { if } j \epsilon B ; \\
& a_{j}^{-}=\min _{i} a_{i j} \quad \text { if } j \epsilon C .
\end{aligned}
$$

The normalization method mentioned above is to preserve the property that the ranges of normalized triangular fuzzy numbers belong to $[0 ; 1]$.

Considering the different importance of each criterion, we can construct the weighted normalized fuzzy decision matrix as

$$
\tilde{V}=\left[\tilde{v}_{i j}\right]_{m x n}, i=1,2, \ldots, \mathrm{m} ; j=1,2, \ldots, \mathrm{n}
$$

where

$$
\tilde{v}_{i j}=\tilde{r}_{i j}(.) d\left(C_{j}\right)
$$

According to the weighted normalized fuzzy decision matrix, we know that the elements $\tilde{v}_{i j} \forall i, j$ are normalized positive triangular fuzzy numbers and their ranges belong to the closed interval $[0,1]$. Then, we can define the fuzzy positive-ideal solution $\left(F P I S, A^{*}\right)$ and fuzzy negative-ideal solution $\left(F P I S, A^{-}\right)$as

$$
\begin{aligned}
A^{*} & =\left(\tilde{v}_{1}^{*}, \tilde{v}_{2}^{*}, \ldots, \tilde{v}_{n}^{*}\right), \\
A^{-} & =\left(\tilde{v}_{1}^{-}, \tilde{v}_{2}^{-}, \ldots, \tilde{v}_{n}^{-}\right),
\end{aligned}
$$

where

$$
\tilde{v}_{j}^{*}=(1,1,1) \text { and } \tilde{v}_{j}^{-}=(0,0,0), \mathrm{j}=1,2, \ldots, \mathrm{n} .
$$

The distance of each alternative from $A^{*}$ and $A^{-}$can be currently calculated as

$$
\begin{aligned}
& d_{i}^{*}=\sum_{j=1}^{n} d\left(\tilde{v}_{i j}, \tilde{v}_{j}^{*}\right), \quad \mathrm{i}=1,2, \ldots, \mathrm{m}, \\
& d_{i}^{-}=\sum_{j=1}^{n} d\left(\tilde{v}_{i j}, \tilde{v}_{j}^{-}\right), \quad \mathrm{i}=1,2, \ldots, \mathrm{m},
\end{aligned}
$$

where $d(.,$.$) is the distance measurement between$ two fuzzy numbers calculating with the following formula:

$$
d(\tilde{\rho}, \tilde{\tau})=\sqrt{\frac{1}{3}\left[\left(\rho_{1}-\tau_{1}\right)^{2}+\left(\rho_{2}-\tau_{2}\right)^{2}+\left(\rho_{3}-\tau_{3}\right)^{2}\right]}
$$

where $\tilde{\rho}=\left(\rho_{1}, \rho_{2}, \rho_{3}\right)$ and $\tilde{\tau}=\left(\tau_{1}, \tau_{2}, \tau_{3}\right)$ are two triangular fuzzy numbers.

A closeness coefficient is defined to determine the ranking order of all alternatives once the $\tilde{d}_{j}^{*}$ and $\tilde{d}_{j}^{-}$of each alternative $A_{i}(\mathrm{i}=1,2, \ldots, \mathrm{m})$ are calculated. The closeness coefficient of each alternative is calculated as

$$
C C_{i}=\frac{\tilde{d}_{j}^{-}}{\tilde{d}_{j}^{*}+\tilde{d}_{j}^{-}}, i=1,2, \ldots, m
$$

Obviously, an alternative $A_{i}$ is closer to the (FPIS, $\mathrm{A}^{*}$ ) and farther from (FPIS, $\mathrm{A}^{-}$) as $\mathrm{CC}_{\mathrm{i}}$ approaches to 1 . Therefore, according to the closeness coefficient, we can determine the ranking order of all alternatives and select the best one from among a set of feasible alternatives.

\subsection{Proposed Methodology}

The proposed fuzzy SWOT model is illustrated by Fig. 2.

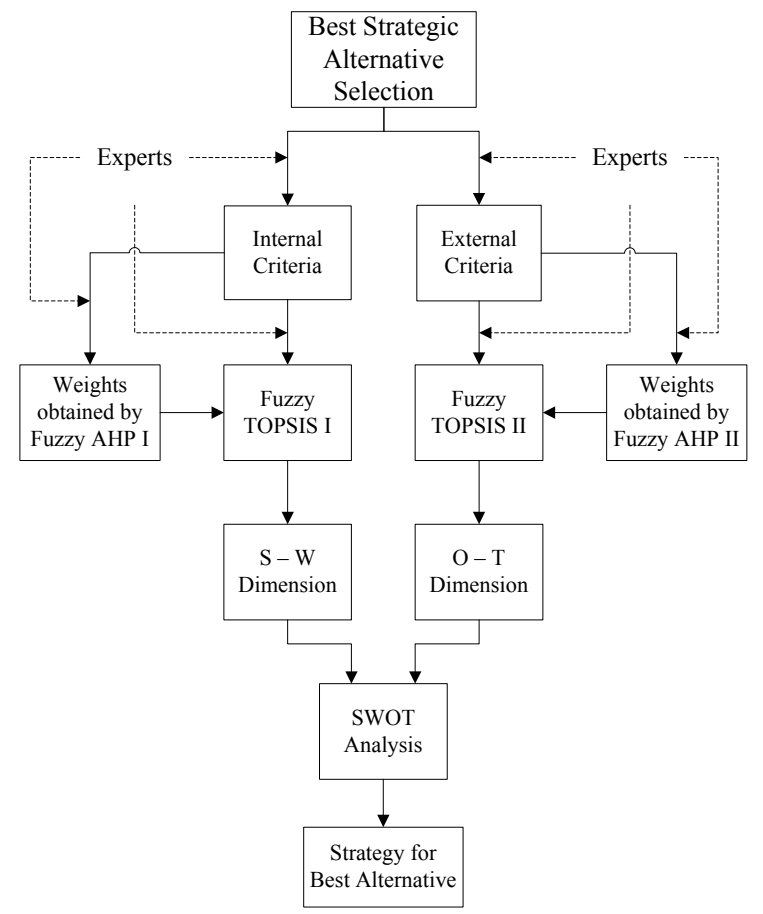

Fig. 2. Flow Chart of the Proposed Fuzzy SWOT analysis.

The proposed fuzzy SWOT can be implemented by succeeding the following steps:

Step1: A group of experts identify the internal and external criteria.

Step2: Appropriate linguistic variables for both internal and external criteria are determined. 
Step3: Two pair-wise comparison matrices for internal and external criteria are constructed, and experts' linguistic evaluations are aggregated to get a mean value for each pair-wise comparison.

Step4: Buckley's approach is used to obtain the weights of both internal and external criteria.

Step5: After determining of strategic alternatives, experts' linguistic evaluations of each strategic alternative with respect to both internal and external criteria are aggregated to get a mean value.

Step6: Fuzzy TOPSIS is utilized for strategic alternative with respect to both internal and external criteria.

Step7: The closeness coefficients of strategic alternatives with respect to both internal and external criteria are calculated.

Step8: Strengths-Weaknesses and OpportunitiesThreats dimensions and their relations are obtained. The results are illustrated on a SWOT relations diagram as shown in Fig. 3.

Step9: The strategic alternative is selected with the largest strength and opportunity scores.

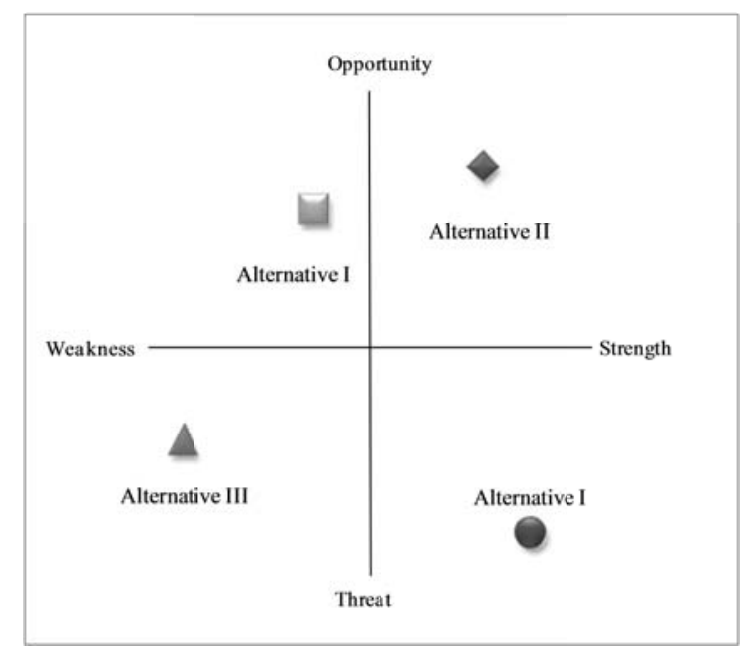

Fig. 3. SWOT relations diagram

\section{An Application to Nuclear Power Plant Site Selection}

Nuclear energy is the conventional energy that arises due to the splitting (fission) or merging together (fusion) of the nuclei of the atom(s). Fission reactors or the thermal nuclear reactors are in commonly used in nuclear power plants. In 2007, there were 439 nuclear power reactors in operation in the world, operating in 31 countries and nuclear power provided $6.3 \%$ of the world's energy and $15 \%$ of the world's electricity. ${ }^{49}$

Nuclear energy and using its technology is a strategic issue that provides an important role for a country in the global energy market. Although the initial investment for a nuclear power plant is too high and building a nuclear power plant causes a fuel dependency to another country, the amount of energy is generated is large and covers the expenses for the mid-term.

The nuclear power plant location selection problem is also analyzed in the literature. ${ }^{49}$ A multi-objective decision analysis method is used to select a site for a nuclear power plant. $^{50}$ Kahraman et al. $(2007)^{51}$ proposed an information axiom based fuzzy approach for the multi-attribute selection of a nuclear power plant location selection in Turkey. The alternative locations were similar to the ones in our study.

The location selection of nuclear power plants is a strategic fuzzy multi-criteria decision making problem. The decision should be madle from a strategic point of view considering the internal and external factors as criteria and the candidate locations should be evaluated by using fuzzy multi-criteria method dealing with ambiguity. Table 3 shows the internal and external criteria. The criteria are brought together by collecting the expert views.

Table 3. The criteria.

\begin{tabular}{l}
\hline INTERNAL \\
\hline IC1: Impact to public and environment \\
IC2: Availability of space for disposal of waste \\
IC3: Distance from populated area \\
IC4: Transport facilities during the erection period \\
IC5 :Distance to industrial energy consumers \\
\hline EXTERNAL \\
EC1: Closeness to the water resources \\
EC2: Climate \\
EC3: Land type \\
EC4: Earthquake risk \\
EC5: Risk for terrorist attack
\end{tabular}

SWOT perspective uses two types of criteria by considering the external and internal environments. The internal criteria are selected with the factors that can be controlled and the external criteria are selected with the factor that cannot be controlled when the decision is made. In the following section the criteria are explained briefly. 


\subsection{Internal Criteria}

Impact to public and environment: The $\mathrm{CO}_{2}$ emissions and the solid wastes of combustion process and liquid wastes of liquid treatment should be the minimum.

Availability of space for disposal of waste: The waste produced by fission in nuclear power plant is generally radioactive which must be disposed properly to avoid health hazards. The waste should either be buried in a deep in the soil or disposed off in a sea quite away from the sea shore. Therefore the site selected for such a plant should have adequate arrangement for the disposal of radioactive waste.

Distance from populated area: The site selected for a nuclear power station should be quite away from the populated areas as there is a danger of presence of radio activity in the atmosphere near the plant. However, as a precautionary measure dome is used in the plant which does not allow the radioactivity to spread by wind or underground waterways.

Transport facilities during the erection period: The site selected for a nuclear power plant should have adequate facility in order to transport the heavy equipments during erection and to facilitate the movement of workers in the plant.

Distance to industrial energy consumers: The distance from the large industrial energy consumers should be low enough in order to decrease the energy loss on the power transmission lines.

\subsection{External Criteria}

Closeness to the water resources: As sufficient of water is required for the cooling purposes, therefore the plant site should be located where certain quantity of water is available such as sea or river.

Climate: The temperature, the speed and way of the wind, humidity, rain regime and the type and the amount of cloudiness in the location of the nuclear power plant affects the operating characteristics of the plant.
Land type: The geographic characteristics of the land of site such as soil and rock stability, natural or artificial slope stability are important while building and providing security for the power plant.

Risk for terrorist attack: From the national security perspective the power plant should be protected location that can be easily defended form all kinds possible terrorist attacks.

Earthquake risk: The location of the power plant should have low earthquake risk because of the security and cost.

\subsection{Strategic Alternatives}

In the nuclear power plant site selection case, there are five strategic alternatives cities composed of Sinop, Mersin, Bursa, Konya, and Van.

Table 4. The characteristic properties of the candidate cities.

\begin{tabular}{ccc}
\hline Candidate Cities & Location inTurkey & Waterside \\
\hline Sinop & North & Black Sea \\
Mersin & South & Mediterranean Sea \\
Bursa & North-west & Marmara Sea \\
Konya & Centre & Salt Lake \\
Van & East & Lake of Van \\
\hline
\end{tabular}

After the determination of internal and external criteria, the experts' evaluations through linguistic variables are used to determine the importance weights of internal criteria by pair-wise comparisons as shown in Table 5 and the importance weights of external criteria by pair-wise comparisons as shown in Table 6 . Then the experts' evaluations through linguistic variables for the strategic alternatives with respect to internal criteria are obtained and closeness coefficients are calculated by utilizing fuzzy TOPSIS as expressed in Table 7. Also experts' evaluations through linguistic variables for the strategic alternatives with respect to external criteria are obtained and closeness coefficients are calculated by utilizing fuzzy TOPSIS as expressed in Table 8 .

Table 5. Evaluations of Experts in Linguistic Variables and Weights of the Internal Criteria

\begin{tabular}{|c|c|c|c|c|c|c|}
\hline & $\mathrm{IC}_{1}$ & $\mathrm{IC}_{2}$ & $\mathrm{IC}_{3}$ & $\mathrm{IC}_{4}$ & $\mathrm{IC}_{5}$ & $\begin{array}{l}\text { Weight Vector } \\
C R: 0.037<0.1\end{array}$ \\
\hline $\mathrm{IC}_{1}$ & $\mathrm{E}, \mathrm{E}, \mathrm{E}$ & SW,E,SS & SS,FS,VS & VS,SS,VS & VS,VS,VS & 0.506 \\
\hline $\mathrm{IC}_{2}$ & & E,E,E & VS,SS,SS & VS,VS,SS & $\mathrm{SS}, \mathrm{SS}, \mathrm{VS}$ & 0.320 \\
\hline $\mathrm{IC}_{3}$ & & & E,E,E & FS,FS,VS & $\mathrm{SS}, \mathrm{FS}, \mathrm{VS}$ & 0.123 \\
\hline $\mathrm{IC}_{4}$ & & & & E,E,E & VW,FW,E & 0.017 \\
\hline $\mathrm{IC}_{5}$ & & & & & E,E,E & 0.034 \\
\hline
\end{tabular}


Table 6. Evaluations of Experts in Linguistic Variables and Weights of the External Criteria

\begin{tabular}{lcccccc}
\hline & $\mathrm{EC}_{1}$ & $\mathrm{EC}_{2}$ & $\mathrm{EC}_{3}$ & $\mathrm{EC}_{4}$ & $\mathrm{EC}_{5}$ & Weight Vector \\
& & & & \\
$\mathrm{EC}_{1}$ & $\mathrm{E}, \mathrm{E}, \mathrm{E}$ & $\mathrm{FW}, \mathrm{FW}, \mathrm{E}$ & $\mathrm{FS}, \mathrm{AS}, \mathrm{AS}$ & $\mathrm{VW}, \mathrm{FW}, \mathrm{SW}$ & $\mathrm{SW}, \mathrm{FW}, \mathrm{FW}$ & 0.163 \\
$\mathrm{EC}_{2}$ & & $\mathrm{E}, \mathrm{E}, \mathrm{E}$ & $\mathrm{VS}, \mathrm{AS}, \mathrm{WS}$ & $\mathrm{E}, \mathrm{SW}, \mathrm{E}$ & E,SS,SS & 0.414 \\
$\mathrm{EC}_{3}$ & & & $\mathrm{E}, \mathrm{E}, \mathrm{E}$ & $\mathrm{FW}, \mathrm{SW}, \mathrm{SW}$ & $\mathrm{SS}, \mathrm{FS}, \mathrm{SS}$ & 0.043 \\
$\mathrm{EC}_{4}$ & & & E,E,E & SS,E,E & 0.267 \\
$\mathrm{EC}_{5}$ & & & & & E,E,E & 0.113 \\
\hline
\end{tabular}

Table 7. Evaluations of Experts in Linguistic Variables for Strategic Alternatives with respectt to Internal Criteria

\begin{tabular}{|c|c|c|c|c|c|c|}
\hline & $\mathrm{IC}_{1}$ & $\mathrm{IC}_{2}$ & $\mathrm{IC}_{3}$ & $\mathrm{IC}_{4}$ & $\mathrm{IC}_{5}$ & $\begin{array}{c}\text { Closeness } \\
\text { Coefficients }\end{array}$ \\
\hline Sinop & $\mathrm{VG}, \mathrm{VG}, \mathrm{G}$ & G,VG,MP & VG,G,G & F,MG,VG & F,MG,MG & 0.248 \\
\hline Mersin & $\mathrm{G}, \mathrm{MG}, \mathrm{MG}$ & G,MG,MP & $\mathrm{G}, \mathrm{G}, \mathrm{F}$ & $\mathrm{MG}, \mathrm{G}, \mathrm{VG}$ & $\mathrm{MG}, \mathrm{MG}, \mathrm{VG}$ & 0.213 \\
\hline Bursa & F,MG,MG & $\mathrm{MG}, \mathrm{F}, \mathrm{G}$ & $\mathrm{P}, \mathrm{P}, \mathrm{MG}$ & $\mathrm{VG}, \mathrm{G}, \mathrm{VG}$ & VG,VG,VG & 0.191 \\
\hline Konya & $\mathrm{F}, \mathrm{F}, \mathrm{F}$ & $\mathrm{MG}, \mathrm{F}, \mathrm{MG}$ & $\mathrm{MG}, \mathrm{F}, \mathrm{MG}$ & $\mathrm{G}, \mathrm{MG}, \mathrm{MG}$ & MP,P,P & 0.170 \\
\hline Van & $\mathrm{G}, \mathrm{MG}, \mathrm{G}$ & $\mathrm{P}, \mathrm{MP}, \mathrm{F}$ & $\mathrm{G}, \mathrm{MG}, \mathrm{F}$ & P,MP,VP & $\mathrm{P}, \mathrm{P}, \mathrm{P}$ & 0.179 \\
\hline
\end{tabular}

Table 8. Evaluations of Experts in Linguistic Variables for Strategic Alternatives with respect to External Criteria

\begin{tabular}{lcccccc}
\hline & $\mathrm{EC}_{1}$ & $\mathrm{EC}_{2}$ & $\mathrm{EC}_{3}$ & $\mathrm{EC}_{4}$ & $\mathrm{EC}_{5}$ & $\begin{array}{c}\mathrm{Closeness} \\
\text { Coefficients }\end{array}$ \\
\hline Sinop & $\mathrm{VG}, \mathrm{VG}, \mathrm{VG}$ & $\mathrm{G}, \mathrm{G}, \mathrm{VG}$ & $\mathrm{G}, \mathrm{MG}, \mathrm{F}$ & $\mathrm{VG}, \mathrm{G}, \mathrm{G}$ & $\mathrm{G}, \mathrm{VG}, \mathrm{VG}$ \\
Mersin & $\mathrm{VG}, \mathrm{VG}, \mathrm{VG}$ & $\mathrm{F}, \mathrm{MG}, \mathrm{MG}$ & $\mathrm{MG}, \mathrm{G}, \mathrm{MP}$ & $\mathrm{G}, \mathrm{G}, \mathrm{G}$ & $\mathrm{MG}, \mathrm{G}, \mathrm{G}$ \\
Bursa & $\mathrm{G}, \mathrm{G}, \mathrm{MG}$ & $\mathrm{MG}, \mathrm{MG}, \mathrm{G}$ & $\mathrm{G}, \mathrm{G}, \mathrm{MP}$ & $\mathrm{P}, \mathrm{MP}, \mathrm{VP}$ & $\mathrm{VG}, \mathrm{VG}, \mathrm{V} \mathrm{G}$ & 0.238 \\
Konya & $\mathrm{MP}, \mathrm{MP}, \mathrm{MP}$ & $\mathrm{MP}, \mathrm{MP}, \mathrm{F}$ & $\mathrm{VG}, \mathrm{G}, \mathrm{VG}$ & $\mathrm{G}, \mathrm{MG}, \mathrm{VG}$ & $\mathrm{VG}, \mathrm{VG}, \mathrm{G}$ & 0.195 \\
Van & $\mathrm{MG}, \mathrm{F}, \mathrm{F}$ & $\mathrm{F}, \mathrm{MP}, \mathrm{MP}$ & $\mathrm{P}, \mathrm{P}, \mathrm{MP}$ & $\mathrm{MP}, \mathrm{P}, \mathrm{MP}$ & $\mathrm{P}, \mathrm{P}, \mathrm{VP}$ & 0,180 \\
\hline
\end{tabular}

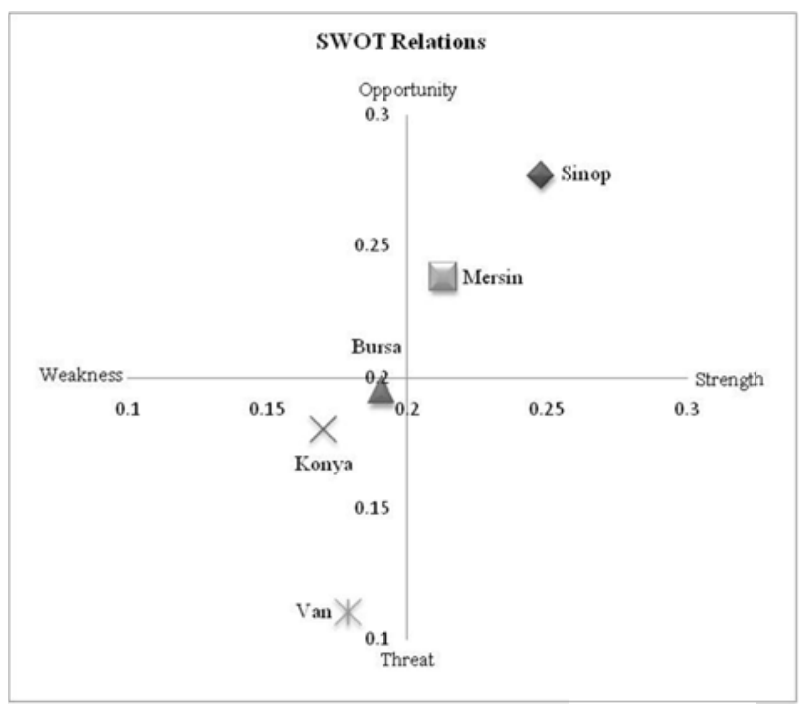

Fig. 4 SWOT relations of Nuclear Power Plant Sites

\subsection{SWOT Relations}

The closeness coefficients are placed on a SWOT relations plane where the horizontal axis shows the strength-weakness and the vertical axis shows the opportunity-threat dimensions. Strength is the highest and weakness is the lowest degree of internal factor scores and opportunity is the highest and threat is the lowest degree of the external or environmental factor scores. The results obtained by fuzzy TOPSIS show the place of the candidate cities according to their closeness coefficients on the plane as represented in Figure 3. The candidate city which is the closest to strength and opportunity is Sinop and it is selected as the best strategic alternative for a possible nuclear power plant site. As shown in Fig. 4, the second best strategic alternative is found as Mersin and the third one is Bursa. When compared with Ref. 48, the same result for the best site location for a nucllear power plant, Sinop, is obtained.

\subsection{Sensitivity Analysis}

In this subsection, we observe if the closeness coefficients of the strategic alternatives are robust or too sensitive to the changes in the weights of the internal and external criteria. First a sensitivity analysis by changing the weights of internal criteria is calculated according to information given in Table 9. The results are represented in Table 10 and Figure 5.

Table 9 - Weights of the internal criteria with respect to the considered cases

\begin{tabular}{cccccc}
\hline & Case0 & Case1 & Case2 & Case3 & Case4 \\
\hline $\mathrm{IC}_{1}$ & 0.51 & 0.40 & 0.20 & 0.20 & 0.15 \\
$\mathrm{IC}_{2}$ & 0.32 & 0.40 & 0.20 & 0.20 & 0.15 \\
$\mathrm{IC}_{3}$ & 0.12 & 0.10 & 0.20 & 0.10 & 0.10 \\
$\mathrm{IC}_{4}$ & 0.02 & 0.05 & 0.20 & 0.25 & 0.30 \\
\hline
\end{tabular}




\begin{tabular}{|c|c|c|c|c|c|c|}
\hline $\mathrm{IC}_{5}$ & 0.03 & 0.05 & 0. & 20 & 0.25 & 0.30 \\
\hline \multicolumn{7}{|c|}{$\begin{array}{l}\text { Table } 10-\text { Closeness coefficients of the strategic alternativ } \\
\text { with respect to the considered cases }\end{array}$} \\
\hline \multicolumn{2}{|c|}{$\begin{array}{l}\text { Strategic } \\
\text { Alternatives }\end{array}$} & $\mathrm{C}_{0}$ & $\mathrm{C}_{1}$ & $\mathrm{C}_{2}$ & $\mathrm{C}_{3}$ & $\mathrm{C}_{4}$ \\
\hline \multicolumn{2}{|c|}{ Sinop } & 0.248 & 0.245 & 0.240 & 0.236 & 0.233 \\
\hline \multicolumn{2}{|c|}{ Mersin } & 0.213 & 0.215 & 0.231 & 0.234 & 0.240 \\
\hline \multicolumn{2}{|c|}{ Bursa } & 0.191 & 0.202 & 0.220 & 0.239 & 0.249 \\
\hline \multicolumn{2}{|c|}{ Konya } & 0.170 & 0.177 & 0.173 & 0.170 & 0.168 \\
\hline \multicolumn{2}{|c|}{ Van } & 0.179 & 0.162 & 0.135 & 0.121 & 0.110 \\
\hline
\end{tabular}

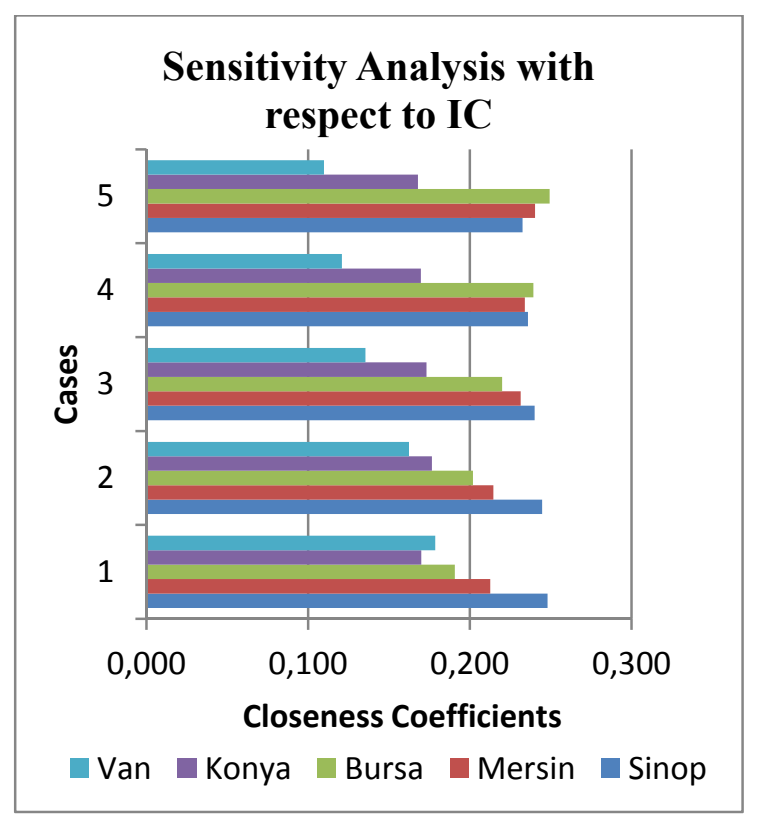

Fig. 5 Sensitivity Analysis with respect to IC considered cases

According to the sensitivity analysis results, as the importance of internal criteria: impact to public and environment, and availability of space for disposal of waste are decreased, and transport facilities during the erection period, and distance to industrial energy consumers, the closeness coefficients of strategic alternatives: Mersin and Bursa increases; Van decreases; and Sinop and Konya stays at same.

Later, another sensitivity analysis by changing the weights of external criteria is calculated according to the information given in Table 11. The results are represented in Table 12 and Figure 6.

Table 11 - Weights of the external criteria with respect to the considered cases

\begin{tabular}{llllll}
\hline $\mathrm{EC}_{1}$ & 0.16 & 0.20 & 0.20 & 0.20 & 0.10 \\
$\mathrm{EC}_{2}$ & 0.41 & 0.35 & 0.20 & 0.20 & 0.10 \\
$\mathrm{EC}_{3}$ & 0.04 & 0.15 & 0.20 & 0.10 & 0.20 \\
$\mathrm{EC}_{4}$ & 0.27 & 0.15 & 0.20 & 0.25 & 0.30 \\
$\mathrm{EC}_{5}$ & 0.11 & 0.15 & 0.20 & 0.25 & 0.30 \\
\hline
\end{tabular}

Table 12 - Closeness coefficients of the strategic alternatives with respect to the considered cases

\begin{tabular}{lccccc}
\hline $\begin{array}{l}\text { Strategic } \\
\text { Alternatives }\end{array}$ & $\mathbf{C}_{\mathbf{0}}$ & $\mathbf{C}_{\mathbf{1}}$ & $\mathbf{C}_{\mathbf{2}}$ & $\mathbf{C}_{\mathbf{3}}$ & $\mathbf{C}_{\mathbf{4}}$ \\
\hline Sinop & 0.277 & 0.267 & 0.261 & 0.266 & 0.260 \\
Mersin & 0.238 & 0.231 & 0.234 & 0.238 & 0.235 \\
Bursa & 0.195 & 0.212 & 0.203 & 0.198 & 0.190 \\
Konya & 0.180 & 0.184 & 0.205 & 0.202 & 0.235 \\
Van & 0.110 & 0.106 & 0.097 & 0.096 & 0.080 \\
\hline
\end{tabular}

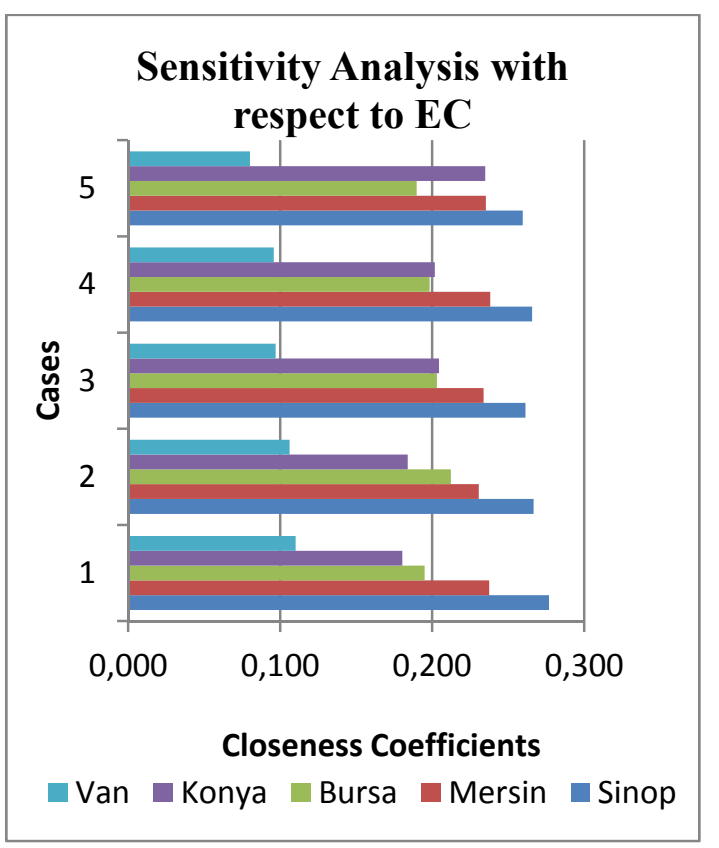

Fig. 6 Sensitivity Analysis with respect to EC considered cases

According to sensitivity analysis results, in all considered cases, the closeness coefficients of the strategic alternatives: Sinop and Mersin stays same. On the other hand, the closeness coefficient of Van decreases as the external criterion earthquake risk increases. 


\section{Conclusion}

SWOT, an early stage of the strategic planning process, has the goal of developing and adopting a strategy resulting in a good fit between internal and external factors. It is a commonly used and important technique for analyzing internal and external environments in order to provide a systematic approach and support for a decision making. In other words, it aims at transforming weaknesses into strengths, and threats into opportunities.

As SWOT is criticized mostly for considering only qualitative examination of environmental factors, no priority for various factors and strategies, and no vagueness of the factors, in this paper in order to overcome these shortcomings a fuzzy multi-criteria SWOT is proposed. The proposed model consists of three parts: first, utilizing Chang's fuzzy AHP to determine the weight vector of internal and external criteria, second, utilizing fuzzy TOPSIS to obtain the ranking results the degree of internal dimension scores from weakness to strength and the degree of external dimension scores from threats to opportunities, and third, determining the best strategic alternative by evaluating the internal and external dimensions.

Turkey is just a pace away to have nuclear power plant. So, nuclear power plant site selection, which is a strategic and important issue for Turkey's energy policy making, is considered as an application case study that demonstrated the applicability of the proposed fuzzy SWOT model. The strategic alternatives are considered as Sinop, Mersin, Bursa, Konya, and Van. The proposed fuzzy SWOT model favors Sinop as the best strategic alternative for nuclear power plant site selection. The same result has also been found in a previous study.

For further research, we suggest other multi-criteria methods like ELECTRE, VIKOR, or Utility Models to be used and the obtained results be compared with the results of this paper.

\section{References}

1. S. Ghazinoory, A. Esmailzadeh and A. Memariani, Fuzzy SWOT analysis, Journal of Intelligent \& Fuzzy Systems 18 (2007) 99-108.

2. J. Kangas, M. Kurtila, M. Kajanus and A. Kangas, Evaluating the management strategies of a forestland estate-the S-O-S approach, Journal of Environmental Management 69 (2003) 349-358.
3. P. Kotler, Marketing Management: Analysis, Planning, Implementation and Control (Prentice-Hall, New Jersey, 1988).

4. M. Kurtila, M. Pesonen, J. Kangas, M. Kajanus, Utilizing the analytic hierarchy process (AHP) in SWOT analysis-a hybrid method and its application to a forest-certification case, Forest Policy and Economics 1 (2000) 41-52.

5. R. Stewart, S. Moamed and R. Daet, Strategic implementation of IT/IS projects in construction: A case study, Automation in Construction 11 (2002) 681-694.

6. H. Weihrich, The TOWS matrix-a tool for situation analysis, Long Range Planning 15(2) (1982) 54-66.

7. S. H. Amin, J. Razmi and G. Zhang, Supplier selection and order allocation based on fuzzy SWOT analysis and fuzzy linear programming, Expert Systems with Applications 38 (2011) 334-342.

8. R. G. Dyson, Strategic development and SWOT analysis at the University of Warwick, European Journal of Operational Research 152 (2004) 631-640.

9. G. Houben, K. Lenie and K. Vanhoof, A knowledgebased SWOT-analysis system as an instrument for strategic planning in small and medium sized enterprises, Decision Support Systems 26 (1999) 125-135.

10. O. Arslan and I. Deha Er, SWOT analysis for safer carriage of bulk liquid chemicals in tankers, Journal of Hazardous Materials 154(1-3) (2008) 901-913.

11. R. Christensen, N. Berg and M. Salter, Policy formulation and administration (Homewood: Richard D. Irwin, 1976).

12. M.K. Masozera, J.R.R. Alavalapati, S.K. Jacobson and R.K. Shresta, Assessing the suitability of communitybased management for the Nyungwe Forest Reserve, Rwanda, Forest Policy and Economics 8 (2006) 206216.

13. M. Kajanus, J. Kangas and M. Kurtila, The use of value focused thinking and the A'WOT hybrid method in tourism management, Tourism Management 25 (2004) 499-506.

14. L. A. Leskinen, P. Leskinen, M. Kurttila, J. Kangas and M. Kajanus, Adapting modern strategic decision support tools in the participatory strategy process - A case study of a forest research station, Forest Policy and Economics 8 (2006) 267-278.

15. H. H. Chang and W. C. Huang, Application of a quantification SWOT analytical method, Mathematical and Computer Modeling, 43(1-2) (2006) 158-169.

16. İ. Yüksel and M. Dağdeviren, Using the analytic network process (ANP) in a SWOT analysis - A case study for a textile firm, Information Sciences 177 (2007) 3364-3382.

17. L. V. Snyder, Facility location under uncertainty: A review, IIE Transactions 38(7) (2006) 537-554.

18. T. Hill and R. Westbrook, SWOT Analysis: It's Time for a Product Recall, Long Range Planning 30(1) (1997) 4652.

19. G. Buyukozkan and O. Feyzioglu, A fuzzy logic based decision making approach for new product development, 
International Journal of Production Economics 90 (2002), 27-45.

20. J. J. Buckley, Fuzzy hierarchical analysis, Fuzzy Sets and Systems 17 (1985) 233-247.

21. C. Chen, Extensions of the TOPSIS for group decisionmaking under fuzzy environment, Fuzzy Sets and Systems 114 (2000) 1-9.

22. A. S. Kheirkhah, A. Esmailzadeh and S. Ghazinoory, Developing strategies to reduce the Risk of hazardous materials transportation in Iran using the method of fuzzy SWOT analysis, Transport 24(4) (2009) 325-332.

23. L. Kuo-liang and L. Shu-chen, A fuzzy quantified SWOT procedure for environmental evaluation of an international distribution center, Information Sciences 178 (2008) 531-549.

24. M. S. Kuo, G. H. Tzeng and S. Y. Chen A new fuzzy quantified SWOT procedure for environmental evaluation of transportation markets, in Proceedings on 17th Symposium on Fuzzy Theory and Its Applications (2009).

25. T. L. Saaty, The Analytic Hierarchy Process (New York: McGraw-Hill.Baker, 1980).

26. T. C. Wang and Y. H. Chen, Applying consistent fuzzy preference relations to partnership selection, International Journal of Management Science 35 (2007) 384-388.

27. N. Y. Seçme, A. Bayrakdaroğlu and C. Kahraman, Fuzzy performance evaluation in Turkish Banking Sector using Analytic Hierarchy Process and TOPSIS, Experts Systems with Applications 36 (2009) 11699-11709.

28. C. Kahraman, U. Cebeci and Z. Ulukan, Multi-criteria supplier selection using fuzzy AHP, Logistics Information Management 16(6) (2003) 382-394.

29. P. M. J. Laarhoven and W. Pedrycz, A fuzzy extension of Saaty's priority theory, Fuzzy Sets and Systems 11 (1983) 229-241.

30. D. Y. Chang, Applications of the extent analysis method on fuzzy AHP, European Journal of Operational Research 95(3) (1996) 649-655.

31. C. Kahraman, Z. Ulukan and E. Tolga, A fuzzy weighted evaluation method using objective and subjective measures, in Proceedings of the international ICSC symposium on engineering of intelligent systems (1998) pp. 57-63.

32. O. Kulak and C. Kahraman, Fuzzy multi attribute selection among transportation companies using axiomatic design and analytic hierarchy process, Information Sciences 170 (2005) 191-210

33. C. L. Hwang and K. Yoon, Multiple attributes decision making methods and applications (Berlin: Springer 1981).

34. M. Ekmekçioğlu, T. Kaya and C. Kahraman, Fuzzy Multicriteria Disposal Method and Site Selection for Municipal Solid Waste, Waste Management 30 (2010) 1729-1736.

35. S. J. Chen and C. L. Hwang, Fuzzy multi attribute decision making, (lecture notes in economics and mathematical system series) (Springer-Verlag New York, vol. 375,1992$)$

36. E. Triantaphyllou, and C. L. Lin., Development and evaluation of five fuzzy multi- attribute decision making methods, International Journal of Approximate Reasoning 14 (1996) 281-310.

37. T. Chu, Selecting plant location via a fuzzy TOPSIS approach, International Journal of Advanced Manufacturing Technology 20 (2002) 859-864.

38. T. Chu and Y. Lin, Improved extensions of the TOPSIS for group decision making under fuzzy environment, Journal of Information and Optimization Sciences $\mathbf{2 3}$ (2002) 273-286.

39. G. R. Jahanshahloo, L. Hosseinzadeh and M. Izadikhah, Extension of the TOPSIS method for decision-making problems with fuzzy data, Applied Mathematics and Computation 181 (2006) 1544-1551.

40. T. C. Chu and Y. C. Lin, An interval arithmetic based fuzzy TOPSIS model, Expert Systems with Applications 36 (2009) 10870-10876.

41. D. Yong, Plant Location Selection Based on Fuzzy TOPSIS, International Journal of Advanced Manufacturing Technologies 28 (2006) 839-844.

42. C.-T. Chena, C.-T. Lin and S.-F. Huangb, A fuzzy approach for supplier evaluation and selection in supply chain management, International Journal of Production Economics (2006), 289-301.

43. C. Kahraman, S. Çevik, N. Y. Ateş and M. Gülbay, Fuzzy multi-criteria evaluation of industrial robotic systems, Computers \& Industrial Engineering 52 (2007) 414-433.

44. T. Kaya. Multi-attribute Evaluation of Website Quality in E-business Using an Integrated Fuzzy AHPTOPSIS Methodology, International Journal of Computational Intelligence Systems 3 (2010) 303-313.

45. S. Perçin. and C. Kahraman. An Integrated Fuzzy MultiCriteria Decision-Making Approach for Six Sigma Project Selection. International Journal of Computational Intelligence Systems 3 (2010) 610-621.

46. A. C. Kutlu and M. Ekmekçioğlu, Fuzzy Failure Modes \& Effects Analysis by Using Fuzzy TOPSIS Integrated with Fuzzy AHP, in 1th International Symposium on Computing in Science\&Engineering (Kuşadası, Aydın, Turkey, 2010).

47. T. Kaya and C. Kahraman, Multicriteria decision making in energy planning using a modified fuzzy TOPSIS methodology, Expert Systems with Applications $\mathbf{3 8}$ (2011) 6577-6585.

48. S. Kim, K. Lee, J. K. Cho and C. O. Kim, Agent-based diffusion model for an automobile market with fuzzy TOPSIS-based product adoption process, Expert Systems with Applications 38 (2011) 7270-7276.

49. International Atomic Energy Agency (2008). Nuclear power plants information. http://www.iaea.org/cgibin/db.page.pl/pris.charts.htm. 
50. C. W. Kirkwood, A case history of nuclear power plant site selection, The Journal of the Operational Research Society, 33 (1982) 353-363.

51. C. Kahraman, S. Çevik Onar, O. Engin, Location selection for a nuclear power plant using an information axiom based fuzzy approach, International Journal of Nuclear Knowledge Management, 4(2) (2007) 422-434.

Published by Atlantis Press

Copyright: the authors 